\title{
The integrity of information created through book entries
}

\author{
DG Gouws \\ School of Financial Sciences \\ University of Pretoria
}

HM van der Poll

School of Accounting

University of Pretoria

\begin{abstract}
We know more about the past than about the future. Accounting information and knowledge of the past come from the fact that the methods we use to arrive at beliefs about the past are generally more reliable than those generating predictions of the future.

Because future uncertainty is linked to the arrow of time, its increase coincides with the flow of time from the past and present to the future. To facilitate and decrease uncertainty, accountants produce an ever-increasing amount of future-oriented information through the use of inter alia book entries. The integrity issues of this method of information creation are investigated in this article. It is found that the integrity of information may be affected when book entries are used.
\end{abstract}

Key words

Book entries

Transactions

Integrity of information

Events

Uncertainty

\section{Introduction}

\subsection{Double entry}

The double entry or duality relationships of accounting events are well known and respected. Goethe calls double entry "one of the fairest inventions of the human mind" (Baxter 1950). Accounting concentrates on the events, transactions and occurrences that can be described as resource flows. Flows necessarily involve a certain dualism, in other words a source and a destination. Therefore, record keeping is " ... depicting a conceived, rather than a fully perceived, flow of resources..." (Goldberg 2001:247). Two possible dimensions are clearly distinguished in Goldberg's statement: "conceived", which refers to a creation of the mind and "perceived", which relates to observing reality.

Accounting is the result of procedures that have been installed to record events, occurrences and transactions that have taken place and decisions that have been taken. They involve change in location, time and condition and may 
also be anticipated or predicted, but they only become actual occurrences when they do happen. In this case, there is no question of reality - the future happenings are made up, a product of the mind. The balance sheet therefore involves a backward as well as a forward-looking dimension.

\subsection{Book entry}

In the literature (Sorter 1969; Johnson 1970; Cushing 1989; Goldberg 2001) a distinction is made between transactions based on observed reality (pure events) and transactions based on predicted or foreseen happenings. Practising accountants use the term "book entries" to describe the latter. Most concepts created on the basis of timing differences are regarded as being created through book entries. Although the book entry is a distinguishable tool in the accounting toolbox, no formal definition could be found. Only one reference to the concept "book entry" and another reference to a similar concept, "intra-entity bookkeeping entries", were found. Lee (1982:19) however states that “. . . depreciation does not represent any financial event occurring during the year - it is simply a book entry". (Own emphasis). Donleavy (1994:62-63) distinguishes between real transactions and judgemental transactions. Judgemental transactions and accounting allocations are seen as "intra-entity entries". The research feedback from the accountants of companies clearly indicates a well-established "book entry" concept.

This paper considers the differences between the integrity of information created by real events and information created by "future events". A book entry is the main mechanism whereby a "future event" is created.

Since Sorter (1969) advocated an "events" approach for accounting and Johnson (1970) clarified certain implications of the events theory, the events approach has had scarcely any impact on accounting theory and research, or on policy making and practice.

\subsection{Qualitative characteristics}

Financial reports prepared by an accountant in the information business should provide adequate information that may be used for making economic decisions. It is essential for all stakeholders to rely with confidence on the information supplied in the company's financial statements. Accountants have to provide the users of financial statements with information that is relevant to the decision to be taken and such information has to be reliable to be useful. These two qualitative characteristics of financial statements are found in the accounting framework AC000 (Hemus, Wingard and Becker 2000). According to the accounting framework, information must display four qualitative characteristics, namely understandability, relevance, reliability and comparability, all of which make the accounting information useful to its users. It is essential that the information should have a high level of integrity, and it is the task of the accountant to ensure that the information is useful and reliable. 


\subsection{Source of accounting information}

The source of information may be divided into two categories: 1) events and 2) "future events". This source is regulated by assumptions, namely matching, accruals, prudence and going concern. According to Hornby (1981), assumptions are good guesses, something "taken for granted" and "supposed but not proved". In the case of accruals, information is created regardless of time or cash, and in the case of prudence, certainty or the best estimate is used to create information.

Events may be seen as reality. Cash is reality and therefore the purest event: "While it is relatively easy for companies to adjust profits to suit their own purposes by enhancing profits at the expense of the balance sheet, creating cash is virtually impossible" (Ellis and Williams 1993). The accountant observes the change in occurrences and events, which is eventually recorded and converted into financial statements. Events are about what has happened. Events that are based on history and reality are contrasted with "future events" that are based on uncertainty and what is likely to happen. The tool that was created to handle these "future events" and uncertainties is the so-called book entry. To create a "future event" is to create something that has not happened yet and is therefore made up and artificial. The word "artificial" is used here in the sense of "human made" and should not evoke negative connotations such as false, not genuine.

Artificially created events serve to facilitate future uncertainties for the following purposes: 1) to achieve certain objectives; 2 ) to account for accounting policy (allocations) - the artificial stop of a continual process; the artificial stop of a continuous process; 3) as an earnings management tool, and 4) even for strategic purposes. Any relevant events are not based on transactions in the actual sense of the word - in other words, they are not based on activities that have taken place, but on "future events" that are necessary to better understand past transactions that are not complete.

There are primarily two types of transactions in the accounting world: objective transactions, based on real events, and subjective transactions, based on future happenings and expectations. According to Goldberg (2001), information available about any given set of circumstances is always about the past, something that has happened, whether it was recently or long ago. Prediction of future happenings and expectations is based either on speculation or, possibly, on deduction from logically recognised assumptions, but nonetheless speculation about what might happen in the future. The information is limited because of the absence of omniscience, not only about the existing state of affairs in total or in general, but also about the composition of the relationships between the numerous elements that makes the information recognisable. If a provision is seen as speculation about what might happen, it is clear that the integrity of information created by book entries might not be the same as the integrity of information created by transactions that are based on facts. 
Year-end constitutes an artificial cut off of a continuous process. On this cutoff, date a problem arises between what happened and what is going to happen. Typical examples of this problem are the benefit received from an asset, and profit that is measured at a certain point in time. Most (1982) states that the matching assumption introduced in 1940 is one of the accounting assumptions that has a direct effect on book entries. It is an assumption made by accountants that there is a cause and effect relationship between expense and revenue over time. According to Wild, Bernstein and Subramanyam (2001) the problems of matching and time were solved with the introduction of accrual accounting.

The application of the matching assumption often has the unfortunate effect of using the balance sheet as a sink of unexpired costs as they await their time of expiry on some future income statement. However, a balance sheet ought to play a more important role than just being a repository of these costs. Although accountants agree that the balance sheet is a source of information about the financial position of the company, the procedures they follow often violate this intended use of a balance sheet (Kam 1990). Deciding which costs should be spread over a period and which not, has a very important effect on the information supplied in the balance sheet, since the balance sheet is a mix of what happened and what is going to happen.

\section{Book entries and accrual accounting}

The Industrial Revolution revealed inadequacies to portray an accurate measure of the net financial result of a company in cash recording. Depreciation, amortisation and the writing off of intangibles were introduced, which means that occurrences that had financial implications as well as those that were directly stated financially were taken into account (Goldberg 2001). When these inadequacies were revealed, the accrual notion was introduced; thereby recording deferred expenses and income. This procedure decreased the matching and timing problems that existed.

Accrual accounting is described as an accounting process of recognising noncash events and circumstances as they occur (Most 1982). Accrual accounting is concerned mainly with future cash receipts and payments, whereas prepayments and deferrals are concerned with past cash receipts and payments. Book entries are seen as non-cash events and pertain to future happenings. To defer is in essence a process of postponing an expense or income item to a later stage. Therefore, when a cash inflow item is deferred, it becomes a liability and when a cash outflow item is deferred, it becomes an asset. Non-cash events are based on the future, whereas cash events are based on the past and present. Since the future holds uncertainty, accountants may create information that has a different integrity than information that is based on past reality.

There are two schools of thought regarding accrual accounting. Advocates of accrual accounting strongly support the concept because they believe it to be superior to cash accounting for reasons of measuring performance and financial 
condition. Critics claim that the main reason for the existence of financial analysis is to unveil accrual accounting and to find the real cash flows. According to Wild et al (2001:101) "[t]hey are troubled by the intricacy of accruals and their susceptibility to manipulation by managers". Book entries are used in accrual accounting and can pave the way for income smoothing or the manipulation of earnings. Critics also view accrual accounting as a combination of "complex and imperfect rules that obscure the purpose of financial statements that of providing information about cash flows and cash generating capacity" (Wild et al 2001:101). The rules of accrual accounting are very flexible and complex and may therefore provide the analyst with information of a lesser integrity than cash accounting.

Kam (1990:69) remarks that "income is based more on accounting constructs than on economic reality." When income is determined under accrual accounting, personal judgements regarding deferrals, allocations and valuations are taken into account. However, in the case of cash flow accounting, personal judgements are minimised. Goldberg (2001:16-17) states that "the primary task of an accountant is to observe, and as an observer an accountant has no judgements to express". When personal judgement comes into play, the integrity of information provided to users may not be the same as the integrity of information based on the facts of real transactions.

\section{Accounting and time}

We know more about the past than about the future. Our knowledge and information of the past comes from the fact that the procedures we use to arrive at beliefs about the past are generally more reliable than those generating predictions of the future.

It is accepted that everything is subject to change. Accountants observe change in the form of events and occurrences that are eventually recorded and converted into financial statements. "Time and reality are closely related. For humans, reality is embedded in the flow of time" (Toffler, 1984:xxix). In order to understand the effect of the flow of time on the accounting discipline, Gouws (2003) relates the widening of accounting to his revision of the accounting concept of time. 
Figure 1 Accounting's arrow of time (Gouws 2003:11)

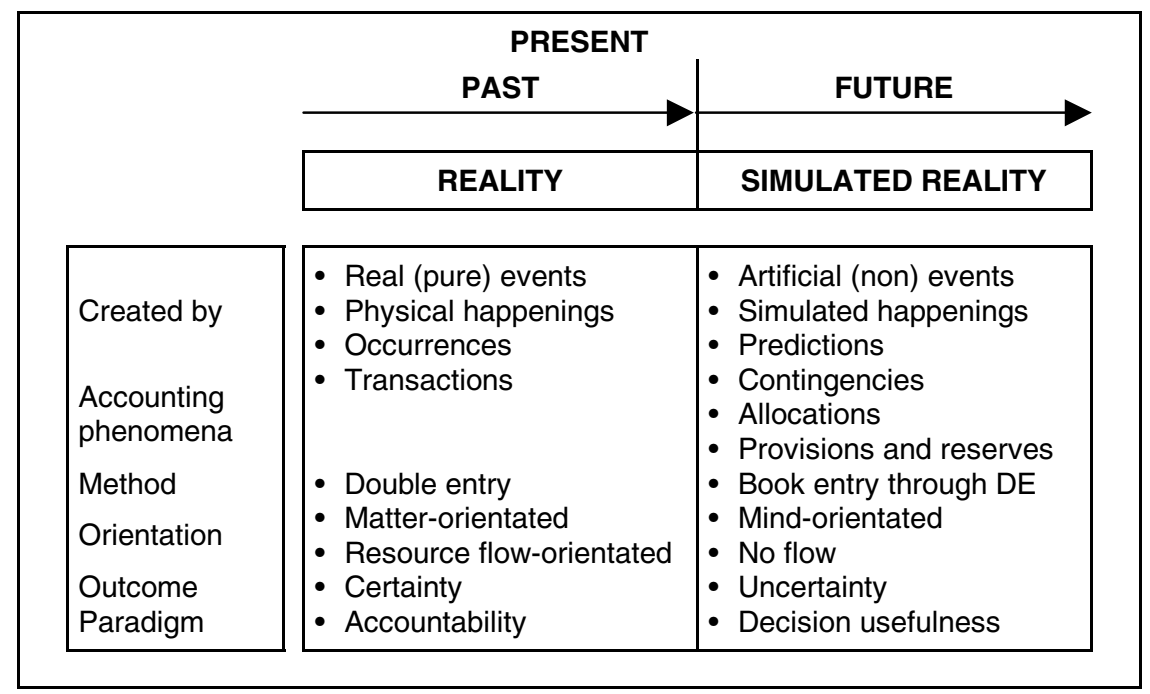

From this diagram it is clear that our transactions are only part of an evolving process over time (Gouws 2003). Because uncertainty is linked to the arrow of time, its increase coincides with the flow of time from the past and present to the future. To decrease uncertainty, accountants produce an ever-increasing amount of "future"-orientated information through the use of inter alia book entries. It is exactly the integrity of this method of information creation that is being investigated in this article.

\section{Research}

\subsection{Purpose of this research}

The purpose of this research is to investigate the difference in the integrity of the information "created" as a result of real events and information "created" as a result of artificial "events" (book entries).

\subsection{Statement of the problem}

Financial statements are made up out of two sources, namely events and "future events". The question arises whether the information created by artificial "events" is on the same integrity scale as the information created by real events, since it is the function of the audit profession to supply integrity of the information.

The accountant is seen as an observer. The Oxford dictionary defines "observe" as the action "to see, to notice and to watch carefully" (Hornby 1981:578). However, when an accountant acts as an observer, he or she becomes judgemental. This viewpoint is further developed by Goldberg (2001:17) in the following remark: "If and when an accountant does express any views about the 
goodness or badness, virtue or vice, integrity or peccability, it is as a moralist perhaps a standard-bearer for a cause - and such views, as suggested, are more than observations of fact: they are based on a personal scheme of values." If an accountant's job description is indeed augmented in this way, then it adds an additional set of responsibilities for the accountant.

\subsection{Research objectives and methods}

\subsubsection{Research objectives}

The research reported on in this paper has the following objectives:

1 To investigate the integrity of information created through book entries.

2 To enhance the quality of financial information.

3 To show how artificial information can manipulate figures, hence the name creative accounting. When companies revalue their assets, there is an opportunity for creative accounting (Griffiths 1995). Revaluation affects the depreciation charge to the income statement, which in turn affects the profit/loss and ultimately the earnings per share as well as the accumulated profit/loss in the balance sheet.

\subsubsection{Research methods}

\subsubsection{Literature review}

A comprehensive literature survey was conducted to understand the nature of book entries. This was basically done in two ways: by studying books and journals from a library, and by using the powerful tool namely the Internet.

\subsubsection{Questionnaire}

A questionnaire was compiled in both MS Word 2000® and Corel Word Perfect® 8 format to test the use of book entries and their effect on the integrity of information. A personal definition of a book entry was also requested.

The following sequence of events was followed in preparing, sending and afterwards analysing the responses from the questionnaire:

Step1: Setting up the questionnaire.

Step 2: Preparing an electronic mailing list.

Step 3: Sending out the questionnaire.

Step 4: Receiving the responses.

Step 5: Recording of the responses.

Step 6: Follow up.

\section{Book entries and their integrity issues}

Book entries refer to the double entries that are used to create inter alia future events. They may have certain effects on the integrity of information contained in the financial statements of companies. One of the respondents to the questionnaire 
commented that in the 1960s a good accountant was judged by the number of book entries he or she used, meaning that the fewer the book entries, the better the accountant.

\subsection{Book entry perspectives from the literature}

According to Cushing (1989) and Sorter (1969) book entries are based on nonevents that include:

$\square$ Accruals;

$\square$ Cost or revenue allocations;

$\square$ Depreciation, depletion and amortisation;

$\square$ Account classifications;

$\square$ Valuations of intangible assets;

$\square \quad$ Financial statement consolidations;

$\square$ Judgements regarding future values of bad debts, natural resource reserves, liabilities under warranties and other contingencies; and

$\square$ Changes in value, such as those associated with the lower-of-cost-or-market method.

It is clear from these examples that non-events make out a substantial part of accounting transactions.

Companies may use book entries as mechanisms to smooth their income or as part of creative accounting (Mulford and Comiskey 2002). Income smoothing is described by Wild et al (2001) as a common form of earnings management, that is, managers may decrease or increase reported earnings to reduce volatility. The method used to smooth income involves adeliberate failure to report part of earnings in profitable years through "creative reserves" or "earnings banks", and the deliberate reporting of these earnings in less profitable years. Smoothing of income already occurred as early as 1944 (Hepworth 1953).

Creative accounting has a somewhat similar description: "Every company in the country is fiddling its profits. Every set of accounts is based on books which have been gently cooked or completely roasted" (Griffiths 1995:vii). When a company puts income smoothing or creative accounting into practice, it follows that the integrity of the information may differ from the integrity of the information created by real transactions.

The opposite of income smoothing is referred to as 'taking a big bath'. This practice is described in detail by Fridson and Alvarez (2002) and may be summarised as follows: If a company suspects that it is going to suffer a decrease in its quarterly profit that will be too large to erase through discretionary items, the company may opt to "take a big bath" by maximising the reported loss. According to market sentiment, investors will not be disturbed much more by a $30 \%$ drop in earnings than by a $20 \%$ drop. The method that is used is usually to accelerate certain future expenses into the current quarter, resulting in earnings 
that are more positive in the following quarter. Applying a 'big bath' may also affect the integrity of the resultant information. If management decides that the truth (real transactions) has to be adjusted, they manipulate information other stakeholders need for decision making, again leading to the observation that information created by book entries may have lesser integrity than information created by real transactions that are based on facts. Management uses book entries as strategic tools and in the long run, this may harm outside stakeholders.

When smoothing of income takes place, the message in the financial statements conveyed to the owner over time is correct, but it signals the wrong message to the decision maker. The biggest motivation behind income smoothing and creative accounting is the fact that the statements are generated for reporting (stewardship) and not decision making. Stakeholders have to be reassured that the company's earnings are stable. Hepworth (1953:53) shares this point of view: "A less tangible, but perhaps more fundamentally important type of advantage of a relatively stable level of periodic income lies in the area of management relations with investors and workers. Certainly, the owners and creditors of an enterprise will feel more confident towards a corporate management which is able to report stable earnings than if considerable fluctuation of reported earnings exists." In this instance the whole truth is not revealed because of the use of book entries, in other words the information used by decision makers and outside stakeholders may be of lesser integrity.

Ellis and Williams (1993:169) claim that "[p]rofits are not necessarily a reliable measure of a company's performance. Companies can adjust profits to suit their own purposes by using provisions." Hence, it seems that book entries are being used to achieve a company's goals. A book entry therefore does not reflect reality; it was created to "smooth" income as well as for other purposes.

As far as the decision maker is concerned, the techniques (book entries) that were used to smooth income provide him or her with "information" that has no integrity for his/her decision-making purposes. This claim is justified as follows:

1 Book entries do not reflect reality.

2 Book entries are subjective and arbitrary, constructed to achieve objectives that are often in conflict with those of the decision maker.

The various book entries that influence the financial statements and weaken messages to the decision maker are part and parcel of the financial statements. These book entries are used as information in the form of numbers, ratios, percentages, etc., while in effect they are based on artificially constructed knowledge. Any "information" created by these processes is therefore considered to have a different integrity.

Financial statements are the main source on which all decision makers and stakeholders base their decisions and they assume that the integrity of the financial information is above board. In a broader context, this research focuses on the integrity of constructed information through book entries, as well as on a new classification system.

Meditari Accountancy Research Vol. 12 No. 12004 : 101-117 
Two specific book entries that were used in this research, as well as their effect on the integrity of information, are the provision for depreciation and the provision for deferred taxation. Both these entries are influenced by time and, therefore, by the matching concept. The latter was heavily criticised by Robert T. Sprouse, who claims that matching creates "unique accounting products ... [such as] . . . deferred charges that are not assets and deferred credits that are not liabilities. The matching concept necessarily relies on ad hoc decisions rather than on accounting theory - on independent value judgements rather than on consistent analysis" (1973:167-168). When looking at the matching concept in this way, it becomes clear that matching takes place rather subjectively. Book entries are most of the time based on the matching concept; hence they may be viewed as subjective in nature too. All this labels the profit or loss calculated in the income statement as little more than just a book entry, because so many book entries are captured to the income statement.

Fridson and Alvarez (2002:300) is quoted to have asked and discussed the following question: "Are deferred taxes part of capital? Near the equity account on many companies' balance sheets appears an account labelled "Deferred Income Taxes". This item represents the cumulative difference between taxes calculated at the statutory rate and taxes actually paid. The difference reflects the tax consequences, for future years, of the differences between the tax bases of assets and liabilities and their carrying amounts for financial reporting purposes. Many analysts argue that net worth is understated by the amount of the deferred tax liability, since it will in all likelihood never come due and is therefore not really a liability at all ... Proponents of this view adjust for the alleged understatement of net worth by adding deferred taxes to the denominator in the totaldebt-to-total-capital calculation."

The above quote highlights another instance where the integrity of information created by book entries is not the same as the integrity of information created by real transactions.

According to the Companies Act, Act No. 61 of 1973, Schedule 4 (South Africa 1973), provision means "any amount written off or retained by way of providing for depreciation, renewals or diminution in value of assets". The question may be asked as to how it is possible to provide for the renewal, retainment, etc., by way of a book entry alone if a book entry is only an artificial event.

\subsection{Results from questionnaire}

At the cut-off date a total of 64 completed questionnaires were received and the response rate was $40.13 \%$. The questionnaire comprised of 21 statements of which the results are discussed below. Feedback received on Questions 16 and 18 does not seem to emphasise the hypothesis. This may be because respondents attached the negative connotation of "false" or "not genuine" to the word "artificial", instead of the connotation of "human made". The remainder of the feedback, however, emphasised the hypothesis. 
Question 1: Book entries precipitated as journal entries may be used to manipulate financial information.

A total of $80 \%$ of respondents agreed that book entries precipitated as journal entries could be used to manipulate financial information. Book entries are not normal transactions and may influence the financial statements positively or negatively. This implies that they are powerful tools at the disposal of an accountant, which must consequently be handled with the greatest caution. From the above it follows that book entries may in fact influence the integrity of information.

Question 2: Classifying items in the balance sheet may be used to manipulate financial information.

A total of $69 \%$ of respondents agreed that classifying items in the balance sheet could be used to manipulate financial information. Since information cannot be created by an accountant, it follows from this response that the integrity of information is influenced by classification. Classification may also be viewed as a book entry.

Question 3: Classifying items for year-end statements can be viewed as reversible book entries.

A total of $51 \%$ of the respondents agreed that classifying items for year-end statements could be viewed as reversible book entries. Items classified in the balance sheet at year end is for only a moment For example, while stock is classified as a current asset for year-end purposes, it is afterwards seen as stock again. The classification of items may be viewed as a book entry and the reclassification of an item may also affect the integrity of information.

Question 4: Providing for depreciation is one way of generating internal funds.

A total of $34 \%$ of the respondents agreed that providing for depreciation is one way of generating internal funds. The large variation in response to this question may be due to respondents' uncertainty about this issue. The obvious next question then is whether the respondents understand the concept of depreciation. There is a difference between accounting and financial management as far as depreciation is concerned. According to financial accounting textbooks, providing for depreciation is a way of creating an internal fund: “...the sum of depreciation and retained earnings (i.e., the cash flow) is an important source of finance" (Wilson 1974:248). Accumulated depreciation provides a company with an internal fund to replace its fixed assets.

Question 5: Earnings management may have a negative effect on the integrity of information.

A total of $66 \%$ of the respondents agreed that earnings management could well have a negative effect on the integrity of information. Earnings management may be defined as "the active manipulation of earnings toward a predetermined target" (Mulford and Comiskey 2002:87). The negative manipulation of information may take place through classification or book entries with the help of 
tools such as income smoothing or taking big baths. It is clear that, if the motivation for earnings management is based on the definition quoted above, the integrity of the information may be affected.

Question 6: Earnings quality should be measured in terms of its usefulness to the users.

A total of $69 \%$ of the respondents agreed that earnings quality should be measured in terms of its usefulness to the users. Earnings quality is dependent upon integrity as determined by the use of book entries, classification and earnings management. Analysts are to a greater extent agreed on this aspect than are financial managers, as their positive response was $78 \%$. The integrity of the information related to earnings quality may be influenced when book entries are used to the benefit of management.

Question 7: The cause and effect of a book entry must be considered for decision-making purposes.

A total of $83 \%$ of the respondents agreed that, for decision-making purposes, the cause and effect of a book entry must be considered when decisions are to be made. Given the response to Question 4 where $34 \%$ of the respondents agreed, and the positive response (83\%) to Question 7, it is clear that all the respondents do not understand the effect of a book entry. The analysts fully agreed on this question $(100 \%)$ whereas they only agreed to some extent in respect of Question $4(44 \%)$.

Question 8: The quality of earnings depends on the time between revenue recognition and cash collection.

A total of $62 \%$ of the respondents agreed that the quality of earnings depends on the length of time that elapses between revenue recognition and cash collection. Revenue recognition occurs when a transaction is not complete, and when the outcome is uncertain and has to be predicted. Revenue recognition is therefore a case of predicting the future, which negatively affects the integrity of information. It is significant that there is such a big difference of opinion among the parties who agreed (62\%) and those who disagreed (32\%) with the statement formulated in this question.

The positive response indicates that the shorter the time between revenue recognition and cash collection, the better the quality of earnings. The analyst gap is smaller: $56 \%$ agreed vs. $44 \%$ who disagreed. There seems to be uncertainty among the analysts. Time is a phenomenon that influences the integrity of information. Matching brought time and future prediction into consideration. A book entry underlying a time-oriented entry also simulates reality, whereas cash represents reality.

Question 9: Book entries affect future reality.

A total of $45 \%$ of the respondents agreed that book entries affect future realities. Therefore, according to the majority of respondents, book entries have little or even no effect on the integrity of information. 
Question 10: Earnings management is used to increase investor confidence.

A total of $64 \%$ of the respondents agreed that earnings management is used to increase investor confidence. Both the analysts and the financial managers felt very strongly that earnings management could increase investor confidence. Earnings management is not only used, but also misused to influence investors, through the use of book entries.

Question 11: Book entries may be used to present 'big baths' in earnings management.

A total of $47 \%$ of the respondents agreed that book entries could be used to present 'big baths' in earnings management. Because $27 \%$ of respondents were not clear on this issue, it could be that 'big baths' was not a well-known term among the respondents. The responses to this question clearly illustrate that book entries influence the integrity of information. According to Lev (2003) companies only start playing around with figures when they get into financial trouble, and then they use book entries. They usually do not manage their earnings. To some extent, managers' ultimate decision to apply big baths or not seems to be based on their perception of right and wrong.

Question 12: Book entries may be used to smooth income over the long term.

A total of $67 \%$ of the respondents agreed, while $31 \%$ disagreed with the statement that book entries could well be used to smooth income over the long term. From the response it is clear that respondents are more familiar with the term 'income smoothing' than 'big baths'. The fact that they agree that book entries are used to smooth income 'over the long term' implies that such actions are future based. This is a slight deviation from Question 9 where the respondents did not agree quite so strongly. Income smoothing is however seen as a tool that may be used by management to influence both the future and the integrity of the informational content of the financial statements.

Question 13: Investors are more confident when a company's earnings rise gradually.

A total of $81 \%$ of the respondents agreed that investors are more confident when a company's earnings rise gradually. Compilers of financial statements also believed that investors are more confident with earnings rising gradually $86 \%$ agreed. It appears, however, that analysts do not really support this belief, since only $55 \%$ agreed with the claim put forward in the question. This might be because analysts look at statements from the investors' point of view.

The statement in Question 13 seems to pressurise compilers of financial statements to conform to income smoothing rules and to use book entries to influence the integrity of the information. Analysts and compilers clearly do not share the same view on this issue. The analysts' response implies that investors are not more confident when a company's earnings rise gradually, because they suspect that the company is playing around with the figures. The high percentage of financial managers who supported the claim in this question indicates that companies will quite easily use income smoothing and thereby influence the integrity of the information.

Meditari Accountancy Research Vol. 12 No. 12004 : 101-117 
Question 14: Income smoothing can be used as a strategic tool.

A total of $63 \%$ of the respondents agreed that income smoothing could be used as a strategic tool, while $32 \%$ disagreed. Income smoothing is one of the methods used to reach a company's strategic goals, as it is used to manipulate the future results of the company. The strategy of a company may influence the integrity of information by making use of book entries.

Question 15: Income smoothing may be viewed as mixing good and bad news to the detriment of outside stakeholders.

A total of $60 \%$ of the respondents agreed that income smoothing could be viewed as mixing good and bad news to the detriment of outside stakeholders. Income smoothing is used to manipulate good (profits) and bad (losses) realities. When income smoothing is applied, the profit of a specific year is used to lower the loss of the previous year. Time is a primary concern when a company is able to reduce the previous year's bad news by simply restating its figures. Since book entries are used to restate the figures of a company, they influence the integrity of the information presented in the financial statements.

Question 16: Book entries are based on artificial transactions.

A total of only $11 \%$ of the respondents agreed that book entries are based on artificial transactions. However, by far the majority of respondents did not share this view. In essence a book entry can, at best, only simulate reality. There is a relationship between the response given here and that given in Question 9 because future uncertainty is also seen as part of artificial transactions. Book entries are the result of a decision to allocate to the future. Allocation is not a real event, whereas cash represents reality. All future-based "transactions" involve uncertainty. It is evident from the responses received that accountants view entries as a result of transactions, while entries as book entries are viewed as similar to real transactions.

Question 17: Information created through income smoothing has less integrity than information created by real events.

A total of $82 \%$ of the respondents agreed that information created through income smoothing has less integrity than information created by real events. Real events create information of a higher integrity than book entries because book entries are based on subjective opinions of management. The quality of integrity is based on information created by real events.

Question 18: Information created through book entries is based on artificial transactions.

A small total of $15 \%$ of the respondents agreed that information created through book entries is based on artificial transactions. This response is in line with the response to Question 16, where only $11 \%$ agreed. It seems that the respondents are not familiar with the term artificial transactions. Book entries are not based on real events but rather on the subjective opinion of management. Respondents do not believe that book entries are based on artificial transactions; they believe they are based on real transactions. This viewpoint may be the result of many respondents not being clear about what a book entry is. 
Question 19: Book entries may seriously affect the integrity of information.

A total of $56 \%$ of the respondents agreed that book entries could seriously affect the integrity of information, while $38 \%$ disagreed on this question. This may be because the respondents do not know the term book entry as well as they should. Analysts more strongly supported the view that integrity of the information is influenced primarily by book entries, as $67 \%$ agreed. Book entries may be used to manipulate information. When earnings management or creative accounting takes place in a company, the integrity of the information may be impaired. Book entries are the main tool used to manipulate information.

Question 20: Only for real transactions and events is cash the main deliverable.

A total of $52 \%$ of the respondents agreed that cash is the main deliverable only for real transactions and events, while $31 \%$ disagreed. An exception to the rule is credit sales where there is a strong degree of uncertainty on the realisation of cash. "While accounts receivable are recorded precisely, their collectibility is not known with precision, but with experience we can get a basis for an acceptable approximation" (Goldberg, 1974). Cash is a very strong determinant of the integrity of the information.

Question 21: Subjective book entries are based on opinions, not facts.

A total of $53 \%$ of the respondents agreed that subjective book entries are based on opinions and not facts. An opinion is perception driven. Book entries are based on the (subjective) opinions of management, which may influence the integrity of the information portrayed in the financial statements. Analysts disagreed strongly on this question, since $67 \%$ gave a negative response. It seems if analysts believe that book entries are based on facts. This may be because of a lack of understanding of the term book entry. It is evident that respondents find it difficult to distinguish between real transactions (reality) and opinions.

Respondents to this questionnaire were very much convinced that book entries influence the quality of the information portrayed in the financial statements.

As a supplement to the questionnaire we asked respondents for their own definition of a book entry and the following definition was supplied by one of the respondents: "An entry that does not have a real (eventual) cash effect on assets or liabilities of the entity and is subject to reversal in certain instances." This definition may be seen as rather apt.

\section{Conclusions and recommendations}

In this paper, the differences in the integrity of information created by real events and information created by "future events" were considered. A book entry is the main mechanism whereby a "future event" is created.

The paper illustrated the following preliminary, though important points:

Meditari Accountancy Research Vol. 12 No. 12004 : 101-117 
1 The integrity of information created by real events differs from that of information created by "future events".

2 Ratios influenced by book entries may severely influence the decision-making process of stakeholders (e.g. management). In particular, it was shown that ratios influenced by the two major book entries, namely depreciation provision and deferred taxation, will differ substantially in interpretation.

3 Responses to the questionnaire used in this research indicate that a large percentage of financial managers agree that the application of earnings management (i.e. taking a big bath or the smoothing of income) influences the integrity of information considerably.

The following recommendations are made:

1 In the light of the results obtained in this work, it is recommended that a new classification for book entries be developed. Book entries influence the integrity of financial information to such an extent that their effect may need to be indicated much more clearly in the financial statements of a company to enable decision makers to make the correct decisions based on high-integrity information.

2 The accounting profession needs to take note of the substantial effect that book entries have on the financial statements of a company and it may need to adjust its auditing principles and approaches.

3 The following definition for book entries is suggested: A book entry is the double entry of a future transaction (without flow or cash effect), which is necessary to understand the past.

\section{Bibliography}

Baxter, W.T. 1950. Studies in Accounting. Sweet and Maxwell, London.

Cushing, B.E. 1989. On the Feasibility and Consequences of a Database Approach to Corporate Accounting. Journal of Information Systems, 3(2):pp.29-52.

Donleavy, G.D. 1994. Cash flow accounting, International uses and abuses, Kent, Routledge.

Ellis, J. and Williams, D. 1993. Corporate Strategy and Financial Analysis. Pitman Publishing, London.

Fridson, M. and Alvarez, F. 2002. Financial Statement Analysis - A Practitioner's Guide. John Wiley and Sons, New York.

Goldberg, L. 1974. Patterns of Accounting Activities. The Saxe Lectures in Accounting. Http://newman.baruch.cuny.edu/digital/saxe/saxe_1974/goldberg_74.htm. (2 June 2003).

Goldberg, L. 2001. A Journey into Accounting Thought. Edited by: Leech, S.L. Routledge, London. 
Gouws, D.G. 2003. Accounting's Time Paradigm. Unpublished research paper. University of Pretoria.

Griffiths, I. 1995. New Creative Accounting - How to make your profits what you want them to be. MacMillan Press Ltd, London.

Hemus, C., Wingard, C. and Becker, H. 2000. GAAP Handbook 2000. Accessio Publishers, Pretoria.

Hepworth, S.R. 1953. Smoothing Periodic Income. In: Financial Accounting Theory 1: Issues and Controversies. McGraw-Hill, New York.

Hornby, A.S. 1981. Oxford Advanced Learner's Dictionary of Current English. Oxford University Press, Oxford.

Johnson, O. 1970. Towards an Events Theory of Accounting. The Accounting Review, 3:641-653.

Kam, V. 1990. Accounting Theory. John Wiley \& Sons, New York.

Lee, G.A. 1982. Modern Financial Accounting. Nelson, Hong Kong.

Lev, B. http://www.facsnet.org/tools/biz_econ/covering_biz/lev.php3. (20 May 2003).

Most, K.S. 1982. Accounting Theory. Grid Inc, Columbus.

Mulford, C.W. and Comiskey, E.E. 2002. The Financial Numbers Game Detecting Creative Accounting Practices. John Wiley \& Sons, New York.

Sorter, H.G. 1969. An "Events" Approach to Basic Accounting Theory. The Accounting Review. January 1969, pp.12-90.

South Africa. 1973. Companies Act, no. 61, 1973. Government Printers, Pretoria.

Sprouse, R.T. 1973. Interrelation between Asset Valuation and Income Determination. Financial Accounting Theory I: Issues and Controversies. McGrawHill, New York.

Toffler, A. 1984. Foreword Science and Change. In: Prigogine I and Stengers I. 1984. Order Out of Chaos. Bantam Books, New York.

Wild, J.J., Bernstein, L.A. and Subramanyam, K.R. 2001. Financial Statement Analysis. McGraw-Hill Higher Education, New York.

Wilson, R.M.S. 1974. Financial Control. McGraw Hill, London. 